\title{
The Delayed Decrease of Seismicity In The Eastern Margin of The Japan Sea Due To The Megathrust Event In 2011 Along The Japan Trench
}

Ritsuko S. Matsu'ura ( $\sim$ matsuura@adep.or.jp)

Association for the Development of Earthquake Prediction (ADEP) https://orcid.org/0000-0002-51088343

Akinori Hashima

Japan Agency for Marine-Earth Science and Technology (JAMSTEC)

Takeo Ishibe

Association for the Development of Earthquake Prediction (ADEP)

\section{Research Article}

Keywords: The eastern margin of the Japan Sea, Seismicity decrease, Viscoelastic aftereffect, Megathrust event, Point-process model selection, Strain rates before and after M9

Posted Date: November 24th, 2021

DOI: https://doi.org/10.21203/rs.3.rs-1069654/v1

License: (c) (i) This work is licensed under a Creative Commons Attribution 4.0 International License.

Read Full License 


\section{Title page:}

2 Title: The Delayed Decrease of Seismicity in the Eastern Margin of the Japan Sea

3 due to the Megathrust event in 2011 along the Japan Trench

4 Author \#1: Ritsuko S. Matsu'ura, Earthquake Research Center, Association for the

5 Development of Earthquake Prediction (ADEP), Chiyoda Build. 8F, 1-5-18, Kanda

6 Sarugaku-cho, Chiyoda-ku, Tokyo, 101-0064, Japan, matsuura@adep.or.jp

7 Author \#2: Akinori Hashima, Research and Development Center for Earthquake and

8 Tsunami Forecasting (FEAT), Research Institute for Marine Geodynamics (IMG), Japan

9 Agency for Marine-Earth Science and Technology (JAMSTEC), 3173-25, Showa-

10 machi, Kanazawa-ku, Yokohama-city, Kanagawa, 236-0001, Japan,

11 hashimaa@jamstec.go.jp

12 Author \#3: Takeo Ishibe, Earthquake Research Center, Association for the Development

13 of Earthquake Prediction (ADEP), Chiyoda Build. 8F, 1-5-18, Kanda Sarugaku-cho,

14 Chiyoda-ku, Tokyo, 101-0064, Japan, ishibe@erc.adep.or.jp

16 Indicate the corresponding author

17 Ritsuko S. Matsu’ura, matsuura@adep.or.jp 
18 Address: Earthquake Research Center, Association for the Development of Earthquake

19 Prediction, Chiyoda Build. 8F, 1-5-18, Kanda Sarugaku-cho, Chiyoda-ku, Tokyo, 101-

20 0064, Japan.

21 (go to new page)

22 


\section{Abstract}

24 In the eastern margin of the Japan Sea, off the west coast of Tohoku district, the

25 seismicity increased right after the M9 megathrust event off the east coast of the Tohoku

26 district on March 11, 2011. Four months later, the seismicity decreased to the half level

27 of that before the M9 event. Such quantitative study was done by the point-process

28 model selection with AIC. The decrease lasted for eight years until an M6.7 event

29 occurred within the area in 2019 . When we compare the seismicity change

30 between before and after the M9 event, with the post seismic change of the maximum

31 shear stress obtained by the viscoelastic simulation for a thousand years after the M9

32 event, we can estimate a loading rate of the shear stress in the area before the M9 as 24

$33 \mathrm{kPa} / \mathrm{y}$. For the term after the M9 event, the rate is a half of it; $12 \mathrm{kPa} / \mathrm{y}$. When we

34 assume the whole dilatation change due to the M9 event had been canceled by the time

35 of the M6.7, the increasing rate of the mean stress after the M9 event is $21 \mathrm{kPa} / \mathrm{y}$ at

36 most. When we will be able to use JMA catalog for 2020 or later years, we can obtain

37 the seismicity level after the M6.7 quantitatively, and we will be able to narrow down

38 this estimation. 


\section{Keywords}

41 The eastern margin of the Japan Sea, Seismicity decrease, Viscoelastic aftereffect,

42 Megathrust event, Point-process model selection, Strain rates before and after M9

43

\section{Main Text}

\section{Introduction}

The M9 mega-thrust inter-plate earthquake, which occurred off the Pacific coast of

47 the Tohoku district on Mar. 11, 2011 (here after "the M9 event"), drastically changed

48 the stress status of the northeastern Japan. The change was reflected as the dramatic

49 activation of seismicity in many areas which had been aseismic before (e.g. Ogata,

50 2012). Many papers were published (e.g. Toda et al., 2011; Ishibe et al., 2015)

51 explaining the change of seismicity in many regions for various receiver fault planes by

52 Coulomb Failure Stress change ( $\triangle \mathrm{CFS})$.

In the eastern margin of the Japan Sea, which is 300 to $400-\mathrm{km}$ away from the

54 center of the source area of the M9 event (Fig. 1) along the direction of the Pacific Plate 
55 (PAC) motion towards the northeastern Japan, the immediate increase of seismicity was

56 also observed like many other regions in Japan. That increase was mainly due to the

57 occurrence of the M6.4 a half day after the M9 event (Table 1). It is a strike-slip type

58 earthquake in the aftershock area of the destructive thrust earthquake of M7.7 in 1983.

59 It was the largest event around the area at that time, since Japan Meteorological Agency

60 (JMA) started to use unified seismic data of Japan for their catalog on Oct. 1, 1997.

61 In that region, we noticed that the significant decrease followed later (Tsumura,

62 personal communication). The decrease sustained for more than a few years. We

63 reported it promptly (Matsu'ura et al., 2017), and waited for the tentative hypocenter

64 catalog of JMA would be revised for the inhomogeneous term after the M9 event.

65 However, the M6.7 thrust event renewed the maximum M of the area on June 18, 2019.

66 Following this event, the seismicity seems to revert to the level before the M9 event.

67 The occurrence of the M6.7 event made us possible not only to describe the decrease of

68 the seismicity, but also to estimate the stress status in the area for eight years after the

69 M9 event.

70 Since the M9 event is gigantic, in addition to the coseismic effect, which is usually 
71 used to explain the seismicity change by $\triangle \mathrm{CFS}$ analysis, the viscoelastic post seismic

72 effect for eight years must be another vital factor to affect the seismicity transition.

73 When we quantitatively compare the post M9-changes of seismicity with the post

74 seismic changes in stress field of the area, it will give us an estimation on the

75 background stress status of the area. Here we examined the seismicity with the latest

76 catalogue of JMA to be compared with the three dimensional simulation on the

77 viscoelastic effect of the M9 event to the area.

78

79 Data and Method for the Seismicity Analysis

80 In Fig.1, the location of the studied area is shown. The A-A' line is parallel to the

81 convergent direction of the Pacific Plate (PAC) toward the northeastern Japan. This line

82 passes through the peak of the co-seismic slip in the focal region of the M9 event

83 obtained by Hashimoto et al. (2012). The area around this line must be the most affected

84 part in the eastern margin of the Japan Sea by the M9 event. In order to prevent

85 intentional selection of earthquakes, events within the $150 \mathrm{~km} \times 300 \mathrm{~km}$ rectangle, whose

86 shorter side is parallel to the line A-A', and whose center is on the line A-A', were 
selected.

We used JMA hypocentral catalog obtained from its website on July 8th, 2021. For

89 the period from Oct. 1st, 1997 to the end of 2019, hypocenters of the depth of $60 \mathrm{~km}$ or

91 days are only 4224. Hereafter, those events plotted as red crosses in Fig. 1 are

92 examined. Among them, the three largest events are listed in Table 1. Although we

93 chose $60 \mathrm{~km}$ as the depth limit, our target seismicity is only that in the shallow crust. We

94 chose $60 \mathrm{~km}$ only to avoid losing some very shallow earthquakes in the early part of the

95 JMA catalog due to the poor depth accuracy for offshore events.

In Fig. 2, cumulative number of the whole data of 22.25 years are shown for the

whole term. Even from the simple cumulative numbers, it is apparent that the seismicity

event, the second largest event of the area (M6.4) was induced within the aftershock 
103 (Ogata, 1988) for the point process analysis in the present study. We excluded the 9\%

104 data in the tail part, which is the half-year period after the largest event of M6.7 on June

10518,2019 , from the analysis to eliminate aftershocks of this largest event. A half year is

106 too short to analyze the seismicity level after the M6.7 confidently. We examined 3844

107 events, which occurred in the 7930 days since Oct. $1^{\text {st }}, 1997$, and focused on the base

108 rate comparison before and after the M9 event.

When $N\left(M_{t h}, S, E\right)$ is number of earthquakes of $\mathrm{M} \geq \mathrm{M}_{\mathrm{th}}$ during the period from $\mathrm{S}$

110 to $\mathrm{E}$, the averaged occurrence rate of $\mathrm{M} \geq \mathrm{M}_{\mathrm{th}}$ for that term; $\lambda\left(M_{t h}, S, E\right)$ is

$$
\lambda_{\text {ave. }}=\lambda\left(M_{t h}, S, E\right)=\frac{N\left(M_{t h}, S, E\right)}{(E-S)} .
$$

112 The Poisson model with the rate $\lambda\left(M_{t h}, 0, T_{a l l} E\right)$ is the simplest point process model

113 that there was no significant change of $\lambda$ temporarily, during the period of $\left\{0, T_{\text {all }}\right\}$.

114 Since the number of parameters $\left(\mathrm{n}_{\mathrm{p}}\right)$ for this model is one, AIC of this model is

$$
\begin{gathered}
A I C_{\text {all }}=\operatorname{AIC}\left(M_{\text {th }}, 0, T_{\text {all }}, n_{p}\right)=2\left(n_{p}-\ln \text { Likelihood }\right) \\
=2-2 \times N\left(M_{t h}, 0, T_{\text {all }}\right)\left(\ln \lambda_{\text {ave. }}-1\right) .
\end{gathered}
$$

117 When $\lambda$ changed at $t=T_{c}, \lambda$ for the term before $T_{c}$, and $\lambda$ for the term after $T_{c}$ are,

$$
\lambda_{\text {left }}=\lambda\left(M_{t h}, 0, T_{c}\right)=\frac{N\left(M_{t h}, 0, T_{c}\right)}{T_{c}}
$$




$$
\lambda_{\text {right }}=\lambda\left(M_{t h}, T_{c}, T_{\text {all }}\right)=\frac{N\left(M_{t h}, T_{c}, T_{\text {all }}\right)}{\left(T_{\text {all }}-T_{c}\right)}
$$

120

121

124 The penalty of introducing Tc in a model is not larger than 12 (Kumazawa et al., 2010).

and AIC of this model is

$$
A I C_{T_{c}}=\operatorname{AIC}\left(M_{t h}, 0, T_{c}, 1\right)+\operatorname{AIC}\left(M_{t h}, T_{c}, T_{\text {all }}, 1\right)+2+\text { Penalty }
$$

$$
A I C_{T_{c}} \leq \max . A I C_{T_{c}}=18-2 \times N\left(M_{t h}, 0, T_{c}\right) \times\left\{\ln \lambda_{\text {left }}-1\right\}
$$

$$
-2 \times N\left(M_{t h}, T_{c}, T_{\text {all }}\right) \times\left\{\ln \lambda_{\text {right }}-1\right\}
$$

125 When $A I C_{T_{c}}<A I C_{\text {all }}$, the model with the rate change is selected, and the $\mathrm{T}_{\mathrm{c}}$ of the best

126 model minimizes $A I C_{T_{C}}$. In order to avoid the effect of inhomogeneity in the long term

127 catalog, $\mathrm{M}_{\text {th }}$ of 2.5 and 3.0 are examined for model selections.

129 Result on the seismicity transition In Fig. 3(a), $\lambda_{\text {left }}$ and $\lambda_{\text {right }}$ of $\mathrm{M}_{\mathrm{th}}=2.5$ are shown at $\mathrm{T}_{\mathrm{c}}$ of each day. When the

131 M6.4 event and its aftershocks became inconspicuous, $\lambda_{\text {right }}$ became rather stable.

132 Models with $\mathrm{T}_{\mathrm{c}}$ within a few-year term after the M9 event give far smaller AIC (Fig.

133 3(c)) than that of Eq. (2). It is confirmed that the occurrence-rate decrease delayed for a

134 few months from the occurrence time of the M9 event (Fig. 3(d)). In order to detect the 
start of that delayed decrease correctly, data within the one month after the M9 event is excluded in the next analysis (Fig. 4). When $\mathrm{M}_{\mathrm{th}}=3.0$, the similar delayed decrease of

137 AIC is also confirmed (Fig. 5). Tcs with smallest three AICs of each model are listed in

138 Table 2 with each occurrence rate. From Figs. 3, 4, and 5, and Table2, it is apparent that

139 the change point Tc is not very sharp. $\lambda_{\text {right }}$ is a half of $\lambda_{\text {left }}$ for each $\mathrm{M}_{\mathrm{th}}$. This

140 delayed decrease started about four months from the M9 event. Even the immediately

141 induced M6.4 event and its aftershocks are included, the delayed decrease is significant

142 (Fig. 3). The decrease rate sustained for more than four years, which made us notice it

143 even from the raw distribution maps of epicenters.

144 Due to the COVID-19, the JMA hypocenter catalog is not yet fixed for 2020 and

1452021 at present. Since available catalog after the M6.7 covers only a half year, we

146 cannot obtain $\lambda$ for the period after M6.7 by eliminating its aftershocks in this study

147 precisely. However, the most right part of Fig. 2 looks that $\lambda$ after the M6.7 at the end of

1482019 is larger than $\lambda_{\text {right }}$. This must be verified in the future study with a longer

149 catalog. In this study, we report that the seismicity decrease to the half level prevailed

150 for eight years after four-month immediate activation after the M9 event. 


\section{Estimation of viscoelastic effect of the M9 event to the area}

154 after the M9 event, not only the coseismic change, but also the post seismic viscoelastic

155 effect of the M9 event should be included consistently. Fortunately, Hashima et al.

156 (2014) already calculated coseismic and post seismic strain fields for a thousand years

157 after the M9 event in the three dimensional space. In Figs. 6 and 7, vertical sections

158 along A-A' line of Fig. 1, of changes in dilatation and the maximum shear strain after

159 the M9 event are shown according to their simulation. They used the coseismic slip

160 distribution of the M9 event obtained by Hashimoto et al. (2012), because the PAC

161 plate geometry (Hashimoto et al., 2004) of the simulation is in common with their

162 source inversion. They simulated the elastic coseismic change and the viscoelastic after

163 effect with the structure shown in Table 3. The area we examined the seismicity is the

164 shallow part of the left end of their simulated region (400 550 km horizontally remoted to the WNW direction from the trench axis on the A-A' line). 
167 point shown in Fig. 6 (10km-depth and $-422 \mathrm{~km}$ from the trench axis on A-A') are

168 plotted. Since that point is in the elastic layer, the dilatation and the maximum shear

169 strain are proportional to the mean stress (the expanding direction is positive), and the

170 maximum shear stress, respectively.

171 The simple approximated expression of the isotropic stress $\sigma_{i s o}(\mathrm{t})$ of the point (-

172422,10 ) at time $t$ (solid line of Fig. 8) is

173

$$
\sigma_{i s o}(\mathrm{t})=0.128+0.104 \times\left(1-\exp ^{-0.057 t}\right) \quad \text { when } t \leq 40 y \text { in } \mathrm{MPa} \text {. }
$$

174

175 The increase rate decays with an exponential function with a half-life of 12 years. About

176 a quarter of the coseismic dilatation increased in 40 years after the M9 event due to the

177 viscoelastic post effect. After around fifty years, $\sigma_{i s o}(\mathrm{t})$ starts decreasing, and only

$17835 \%$ of the coseismic dilatation is left at $\mathrm{t}=1000 \mathrm{y}$ (see Fig. 10 of Hashima et al., 2014)

179 in this region.

180 The maximum shear stress $S_{\max }(\mathrm{t})$ (broken line in Fig. 8) can be expressed as

$$
S_{\max }(t)=(0.194+0.014 t) \quad \text { when } \mathrm{t} \leq 3 \mathrm{y}
$$

$$
S_{\max }(t)=S_{\max }(3)+0.26 \times\left(1-\exp ^{-0.047(t-3)}\right) \text { when } 3 \mathrm{y}<\mathrm{t} \leq 40 \mathrm{y} \text { in } \mathrm{MPa}
$$


183 For the first three years, $s_{\max }$ increases almost linearly. Then the increase rate decays

184 with an exponential function with a half-life of 14.75 years. In the examined area, the

185 post seismic maximum shear stress change for 40 years is a half of the coseismic

186 change. As Fukahata and Matsu'ura(2018) pointed out, even the viscosity is set to be

$18710^{19} \mathrm{~Pa} \mathrm{~s}$, the relaxation time at this point is larger than 10 years. The relaxation time of

188 the isotropic stress is slightly shorter than that of maximum shear stress in the studied

189 area. After around a hundred years, the maximum shear stress starts decreasing in this

190 region. However, only $7 \%$ of its value at $\mathrm{t}=100 \mathrm{y}$ decreases at $\mathrm{t}=1000 \mathrm{y}$ (see Fig. 11 of

191 Hashima et al., 2014).

192 The coseismic changes of the mean stress, and of the maximum shear stress at the

193 point are 0.13 $\mathrm{MPa}$, and 0.19 $\mathrm{MPa}$, respectively. After eight years $(\mathrm{t}=8)$, these increased

194 to $0.17 \mathrm{MPa}$, and 0.29 MPa, respectively. Until the thrust-type M6.7 occurred in 2019,

195 the post seismic dilatation was $30 \%$ of the coseismic dilatation, while the post seismic

196 maximum shear stress increase was the half of the coseismic change. 
often easy to be detected regardless of the seismicity status before that large event. The

201 ETAS effect boosts the detectability of seismicity increase. It is no wonder that DeVries

202 et al. (2018) selected $\Delta \tau_{\max }$ that corresponds only to the activation (Matsu'ura and

203 Terakawa, 2021) as the best indicator for predicting spatial patterns of aftershocks.

204 However, what we found this time is the decrease to the half level that lasted for eight

205 years after the main shock. In our case, $\Delta \tau_{\max }$ is not a good indicator at all. Since $\Delta \mathrm{CFS}$

206 depends on the orientations of receiver faults, it can be used to explain the decrease of

207 seismicity as well as the increase. However, it is impossible to determine fault

208 orientations of all 3884 events we analyzed. $\Delta$ CFS is not very effective to what we

209 found.

210

As Terakawa et al. (2013) pointed out, the occurrence of the M6.4 should be

211 affected by the change of pore fluid pressure in the aftershock area of the 1983 event. Its

212 fault orientation was not at all favorable to the background stress field, which is roughly

214 expanded $\triangle \mathrm{CFS}$ to the change of energetics-based Failure Stress $(\Delta \mathrm{EFS})$ as the index 
215 for predicting induced seismicity after a large event. $\triangle \mathrm{EFS}$ does not depend on the

216 orientations of receivers, and it does include the change of pore fluid pressure due to a

217 large earthquake. In the four month-period between the occurrence time of the M9 event

218 and the Tc determined in the third section, $\triangle \mathrm{EFS}$ must be used for the analysis, since

219 the change of pore fluid pressure in the studied area should have affected the seismicity.

220 However, after Tc, the seismicity of the area is so stable for eight years. We can treat

221 the pore fluid pressure after Tc as a part of the background stress field, which should

222 have been changing very smoothly in the area, after the drastic change of pore fluid had

223 been settled before Tc.

224 Therefore, we assume that the gradually changing crustal stress after Tc was the

225 summation of the background tectonic stress and the coseismic and post seismic stress

226 changes due to the M9 event. The post-seismic increase of $96 \mathrm{kPa}$ in the maximum

227 shear stress for eight years resulted in the post seismicity of the area. To sustain the

228 double level of seismicity for years before the M9 event, the double of the post maximum shear stress change is necessary. It give us $24 \mathrm{kPa} / \mathrm{y}$ in the studied area as the tectonic accumulation rate of shear stress before the M9 event. This rates give us a 
recurrence time estimation of about two hundred years for a major event of this area

232 with $5 \mathrm{MPa}$ stress drop. As the shear strain rate, it is equivalent to $4 \times 10^{-7} / \mathrm{y}$.

233 When we assume that the dilatation due to the M9 event, including both coseismic

234 and post seismic changes, had been almost canceled by the time of the M6.7 in the

235 studied area, the tectonic rate of the compressional stress in this area after the M9 event

236 becomes $21 \mathrm{kPa} / \mathrm{y}$. It is also equivalent to the strain rate of $4 \times 10^{-7} / \mathrm{y}$. If we assume that

237 the recovery was half of the pre-M9 level at the time of M6.7, the rate is $10 \mathrm{kPa} / \mathrm{y}$. In

238 order to determine the current mean stress status, we should examine the post M6.7

239 seismicity quantitatively in future study with a catalog with the extended period.

240 As the order estimation of the background loading rate in the eastern margin of the

241 Japan Sea, we get $24 \mathrm{kPa} / \mathrm{y}$ of shear rate for the term before the M9 event, and $12 \mathrm{kPa} / \mathrm{y}$

242 of shear rate for the term after the M9 event. Since the seismicity decrease we found

243 was stable for eight years, ignoring the effect of changes in the pore fluid pressure of the

244 area does not affect our estimations seriously. We also ignore the effect of after slips

245 around the source area of the M9 event, because the studied area is more than $150 \mathrm{~km}$

246 away from the regions slipping afterwards. As the background accumulation rate of 
247 compressional mean stress after the M9 event, we get $21 \mathrm{kPa} / \mathrm{y}$ or lower. With the

248 analysis of the seismicity after the M6.7 event, it will be better to use $\Delta \mathrm{EFS}$ to examine

249 post-M9 mean-stress status further.

250 The rate of horizontal strain obtained from GPS data for the eastern margin of the

251 Japan Sea before the M9 event (Sagiya, 2004) is a quarter of what we obtained in this

252 study. Fukahata et al. (2020) obtained EW-direction deformation rates from GPS data in

253 the Niigata region as $6 \times 10^{-8} / \mathrm{y}$ for pre-M9, and $3 \times 10^{-8} / \mathrm{y}$ for post-M9 terms. Their strain

254 rates are two dimensional. Plane strain is usually smaller than three-dimensional strain.

255 It is considered that rates we obtained are within the permissible range of the GPS

256 observation. The shear strain rate for the post-M9 term we obtained is a half of the pre-

257 M9 term. It is coincide with what Fukahata et al (2020) obtained.

\section{Conclusion}

259

We examined the delayed decrease of seismicity of the area in the eastern margin

260 of the Japan Sea with the point process model selection. The area remotes $300-400 \mathrm{~km}$

261 horizontally away along the plate motion direction from the center of the mega-thrust 
induced M6.4 strike-slip event. After about four months, the seismicity became the half

264 level of that before the M9 event. The decreased rate lasted for eight years. After 8.25

265 years, an M6.7 thrust-type event occurred in the area. Due to the aftershocks of this

266 event, we cannot determine the base occurrence rate at present yet with the fixed JMA

267 catalogue. However, the raw cumulative number curve suggests that the seismicity is

268 recovering after the M6.7.

269 Referring the viscoelastic simulation, the coseismic and post seismic dilatation

270 change for eight years due to the M9 was examined. It gives the $21 \mathrm{kPa} / \mathrm{y}$ as the

271 maximum tectonic increase rate of mean compressional stress on this area after the M9

272 event, when we assume the occurrence of the M6.7 represents the full recovery of the

273 compressional stress field in the eastern margin of the Japan Sea. When the JMA

274 catalogue will allow us to analyze seismicity after the M6.7 fully, the mean stress level

275 at present will be clearer.

277 seismicity after the M9 event, the pre-M9 seismicity in the area suggests $24 \mathrm{kPa} / \mathrm{y}$ as the

278 rate of tectonic shear stress increase before the M9 event. The estimated loading rates of 
282 (Fukahata et al., 2020). For a long-term hazard estimation of the eastern margin of the

283 Japan Sea area, the rates we obtained will be another proxy values.

\section{Declarations}

Not applicable

\section{Consent for publication}

\section{List of abbreviations}


JMA: Japan Meteorological Agency

PAC: the Pacific Plate

\section{Availability of data and materials}

298

Mw, mechanism, and hypocentral depth of centroid moment tensor

solutions for most major events in and around Japan are available at the

F-net website: https://www.fnet.bosai.go.jp/top.php?LANG=en (obtained

301

on July 8,2021$)$.

302

303

svd/eqev/data/bulletin/hypo.html. (obtained on July 8, 2021) However,

304

JMA revises the past hypocenter catalogues irregularly. Most revisions

305

are usually trifling matters.

306

307

308

Funding

309

This study was funded by the Ministry of Education, Culture, Sports,

310 


\section{Authors' contributions}

313

Ritsuko S. Matsu'ura analysed the seismicity. Akinori Hashima prepared

the viscoelastic calculations. Takeo Ishibe examined the F-net data in the area for the discussion.

\section{Acknowledgements}

Dr. Kenshiro Tsumura first found the seismic quiescence in the eastern margin of the Japan Sea and encouraged us to analyze it quantitatively.

This study was funded by the Ministry of Education, Culture, Sports,

Science and Technology (MEXT) for Headquarter of Earthquake Research Promotion (HERP) of the Japanese government.

\section{Authors' information}

323

\section{References}

325 DeVries, P.M.R., Viégas, F., Wattenberg, M., Meade, B.J. (2018) Deep learning of 326 aftershock patterns following large earthquakes. Nature 560, 632-634. doi.org/10.1038/ 
s41586-018-0438-y

328 Fukahata, Y. \& Matsu'ura, M. (2018) Characteristics of viscoelastic crustal deformation

329 following a megathrust earthquake: discrepancy between the apparent and intrinsic

330 relaxation time constants, Pure Appl. Geophys., 175, 549-558, doi: 10.1007/s00024-

$331 \quad 017-1735-3$

332 Fukahata, Y., Meneses-Gutierrez, A., Sagiya, T. (2020) Detection of plastic strain using

333 GNSS data of pre- and post-seismic deformation of the 2011 Tohoku-oki earthquake,

334 Earth Planets Space, 72:18, doi.org/10.1186/s40623-020-1144-1.

335 Hashima, A., Fukahata, Y., Hashimoto, C., Matsu'ura, M. (2014) Quasi-static strain and

336 stress fields due to a moment tensor in elastic-viscoelastic layered half-space, Pure

337 Appl. Geophys., 171: 1669-1693.

338 Hashimoto, C., Fukui, K., Matsu'ura, M. (2004) 3-D modelling of plate interfaces and

339 numerical simulation of long-term crustal deformation in and around Japan, Pure Appl.

340 Geophys., 161: 2053-2068.

341 Hashimoto, C., Noda, A., Matsu'ura, M. (2012) The Mw 9.0 northeast Japan

342 earthquake: total rupture of a basement asperity, Geophys. J. Inter., 189: 1-5. 
344 Ishibe, T., Shimazaki, K., Satake, K. (2011) Change in seismicity beneath the Tokyo 345 metropolitan area due to the 2011 off the Pacific coast of Tohoku Earthquake. Earth 346 Planet Sp 63, 40. https://doi.org/10.5047/eps.2011.06.001

347 Kumazawa, T., Ogata, Y., Toda, S. (2010) Precursory seismic anomalies and transient 348 crustal deformation prior to the $2008 \mathrm{Mw}=6.9$ Iwate-Miyagi Nairiku, Japan,

349 earthquake, J. Geophys. Res., 115, B10312, doi:10.1029/2010JB007567.

350 Matsu'ura, M., Terakawa, T. (2021) Decomposition of elastic potential energy and a

351 rationla metric for aftershock generation, Geophys. J. Int. (2021) 227, 162-168.

352 https://doi.org/https://doi.org/10.1093/gji/ggab206.

353 Matsu'ura, R. S., Ishibe, T., Tsumura, K. (2017) Significant Decrease of Seismicity in 354 the Northeastern Margin of the Japan Sea after the Mega Thrust Event on Mar. 11, 355 2011, Proceedings JpGU-AGU Joint Meeting 2017, SSS05-10. (p.14-15 of the pdf 356 available at: http://www2.jpgu.org/meeting/2017/PDF2017/S-SS05_O_e.pdf).

357 Ogata, Y. (1988) Statistical models for earthquake occurrences and residual analysis for 358 point processes, J. Am. Statist. Asso., 83(401), 9-27. https://doi.org/10.2307/22889149- 
360 Ogata, Y. (2012) Long-term probability forecast of the regional seismicity that was

361 induced by the M9 Tohoku-Oki earthquake, Rep. Coordinating Committee for Earthq.

362 Prediction, 88, $92-99$ (in Japanese).

363 Sagiya, T. (2004) A decade of GEONET: 1994-2003 - The continuous GPS

364 observation in Japan and its impact on earthquake studies-. Earth Planet Sp., 56, xxix-

365 xli. https://doi.org/10.1186/BF03353077

366 Terakawa, T., Hashimoto, C., Matsu'ura, M. (2013) Changes in seismic activity

367 following the 2011 Tohoku-oki earthquake: Effects of pore fluid pressure. Earth Planet.

368 Sci. Lett., 365. 17-24. doi:10.1016/j.epsl.2013.01.017

369 Terakawa, T., Matsu'ura, M. Noda, A. (2020) Elastic strain energy and pore fluid

370 pressure control of aftershocks, Earth planet. Sci. Lett., 535, 16103.

371 https://doi.org/10.1016/j.epsl.2020.116103.

372 Toda, S., Ross, S., Lin, J. (2011) Widespread seismicity excitation throughout central

373 Japan following the $2011 \mathrm{M}=9.0$ Tohoku earthquake and its interpretation by Coulomb

374 stress transfer, Geophys. Res. Lett., 38, L00G03, 


\section{Figure Captions}

378 Fig. 1. The map of the examined area, and the distribution of examined shallow

379 earthquakes.

380 All $\mathrm{M}>=2.0$ earthquakes of depth $=<60 \mathrm{~km}$ in JMA catalog from Oct. $1^{\text {st }}, 1997$, to Dec.

$38131^{\text {st }}, 2019$ in the black dotted square of the left map are shown by gray crosses in the

382 right large map. Red crosses are analyzed earthquakes. M6.4 on 2012 Mar. 12 (JST) in

383 the north, and M6.7 on 2019 June 18 in the southeast are the only two $M \geq 6.0$ events.

384 Source area of the megathrust M9 event in 2011 is after Hashimoto et al. (2012).

385 Ticks for each $100 \mathrm{~km}$ are shown for the A-A' line, which is parallel to the PAC-plate

386 motion, is the same as the line in Fig. 7 of Hashima et al. (2014).

387

388 Fig. 2. Cumulative number of events shown by red crosses in Fig. 1.

389 (a) M-T plot of events. (b) Cumulative numbers of the whole term with three thresholds

390 of M. For the period around the occurrence time of the M9 event (shown by gray 
391 squares on each line) are expanded in (c), (d) and (e), respectively. The slope of five

392 occurrence rates are shown by black lines as references to see rates from cumulative

393 number lines.

394

395 Fig. 3. Occurrence rates and AIC at each Tc for $\mathrm{M} \geq 2.5$.

396 (a) Daily occurrence rate of before Tc (Blue line) and after Tc (Red line) terms are

397 shown at each Tc. Black line shows the average rate of the whole term.

398 (b) $\mathrm{M}-\mathrm{T}$ plot of $\mathrm{M} \geq 2.5$ for the same period.

399 (c) AIC values for each Tc are plotted at Tc. The black line shows the AIC for the

400 model without Tc, i.e. the constant rate through the whole term. The part in the red

401 broken square are expanded in (d).

402

$403 \quad$ Fig. 4

404 . Occurrence rates and AIC at each Tc for $\mathrm{M} \geq 2.5$ without one month data after the M9

405 event.

406 Tc in July 2011 gives the smallest AIC. See the caption of Fig. 3. 
408 Fig. 5. Occurrence rates and AIC at each Tc for $\mathrm{M} \geq 3.0$ without one month data after the

409 M9 event.

410 Tc in Aug. 2011 gives the smallest AIC. See the caption of Fig. 3

412 Fig. 6. Temporal changes of the isotropic strain due to the M9 event.

413 The vertical section of the isotropic strain changes along the line A-A' in Fig. 1 at $\mathrm{t}=0$

414 (coseismic), 5, 10, 20, 30, 50, and 100 years after the M9 event are shown by color and

415 contours. The red and blue color scales represent expansion, and contraction,

416 respectively. Contours of $5 \times 10^{-5}, \pm 2 \times 10^{-5}, \pm 1 \times 10^{-5}, \pm 5 \times 10^{-6}, \pm 2 \times 10^{-6}$ are also shown by

417 thin lines. The thick solid line indicates the PAC plate interface shallower than $50 \mathrm{~km}$.

418 The thin horizontal line at 40km-depth indicates the interface between elastic and

419 viscoelastic layers. The analyzed area is shown by the blue dotted rectangle in the top

420 figure. The green star in the top figure shows the position of the point whose stress

421 change is plotted in Fig. 8. [made after Hashima et al. (2014)] 
423 Fig. 7. Deviatoric shear strain changes due to the M9 event.

424 The vertical section of the deviatoric strain fields along the line A-A' in Fig. 1 at $t=0$

425 (coseismic), 5, 10, 20, 30, 50, and 100 years after the M9 event.

426 The deviatoric maximum shear strain is shown by color, and contours of $5 \times 10^{-5}$,

$4272 \times 10^{-5}, 1 \times 10^{-5}, 5 \times 10^{-6}$, and, $2 \times 10^{-6}$. The black and white bars show the extension and

428 contraction directions with those magnitudes at each point, respectively. See the caption

429 of Fig. 6.

430

431 Fig. 8. Changes of the mean stress (extension positive), and the maximum shear stress

432 at the point of (422km-west from the trench axis, 10km-depth) shown in Fig. 6 due to

433 the M9 event, for 50 years.

434 Since the point is in the elastic layer, dilatation and the maximum shear strain are

435 proportional to the mean stress, and the maximum shear stress, respectively. With the

436 bulk and shear moduli in Table 3 , these are converted to stresses. The values at $\mathrm{t}=0$ are

437 coseismic values. 
440 Table 1. List of the three largest earthquakes in the studied area during Oct. 1997-Dec.

4412019.

\begin{tabular}{ccccc} 
Date (JST) & JMA M & Mw & depth $(\mathrm{km})$ & type \\
\hline 1997/11/23 12:50 & 5.8 & 5.5 & 8 & thrust \\
2011/3/12 4:46 & 6.4 & 6.1 & 5 & strike slip \\
2019/6/18 22:22 & 6.7 & 6.4 & 11 & thrust \\
\hline
\end{tabular}

$442 \quad$ Mw and depth are from F-net.

443 Table 2. List of Tc with three smallest AICs for each model

\begin{tabular}{cccccccccc} 
Tc in & days after & & & & & & \\
2011 & the M9 & $\mathrm{AIC}_{2.5 \mathrm{w} / \mathrm{c}}$ & $\mathrm{AIC}_{3.0 \mathrm{w} / \mathrm{c}}$ & $\mathrm{AIC}_{2.5}$ & $\lambda_{\text {leff2.5w/c }}$ & $\lambda_{\text {right2.5 }}$ & $\lambda_{\text {left3w/c }}$ & $\lambda_{\text {right3w/c }}$ & $\lambda_{\text {right2.5 }}$ \\
\hline July 3 & 113 & $\underline{7176.4}$ & 3563.4 & $\underline{7354.8}$ & 0.20 & 0.10 & 0.073 & 0.036 & 0.21 \\
July 24 & 134 & 7176.5 & 3562.1 & 7355.0 & 0.20 & 0.10 & 0.073 & 0.035 & 0.21 \\
Aug. 10 & 151 & 7178.4 & $\underline{3561.9}$ & 7357.1 & 0.20 & 0.10 & 0.073 & 0.035 & 0.21 \\
\hline
\end{tabular}

444 Underlined value is the smallest AIC for each data set. A numerical subscript for AIC

445 and $\lambda$ represents Mth of each data set. "w/c" represents that the data without a month

446 after the M9 event is used. All $\lambda \mathrm{s}$ are occurrence rates per one day.

449 Table 3. The structural parameter of the elastic-viscoelastic layered half-space model used for the simulation (after Hashima et al., 2014). 


\begin{tabular}{cccccc}
$\begin{array}{c}\text { Layer } \\
\text { No. }\end{array}$ & $\begin{array}{c}\text { Thickness } \\
(\mathrm{km})\end{array}$ & $\begin{array}{c}\text { Bulk } \\
\text { modulus } \\
\left(10^{10} \mathrm{~Pa}\right)\end{array}$ & $\begin{array}{c}\text { Shear } \\
\text { modulus } \\
\left(10^{10} \mathrm{~Pa}\right)\end{array}$ & $\begin{array}{c}\text { Dencity } \\
\left(10^{3} \mathrm{~kg} / \mathrm{m}^{3}\right)\end{array}$ & $\begin{array}{c}\text { Viscosity } \\
\left(10^{19} \mathrm{~Pa} \mathrm{~s}\right)\end{array}$ \\
\hline 1 & 40 & 5.1 & 3.2 & 2.6 & $\infty$ \\
2 & $\infty$ & 13 & 6.9 & 3.4 & 1 \\
\hline
\end{tabular}

451 
Figures

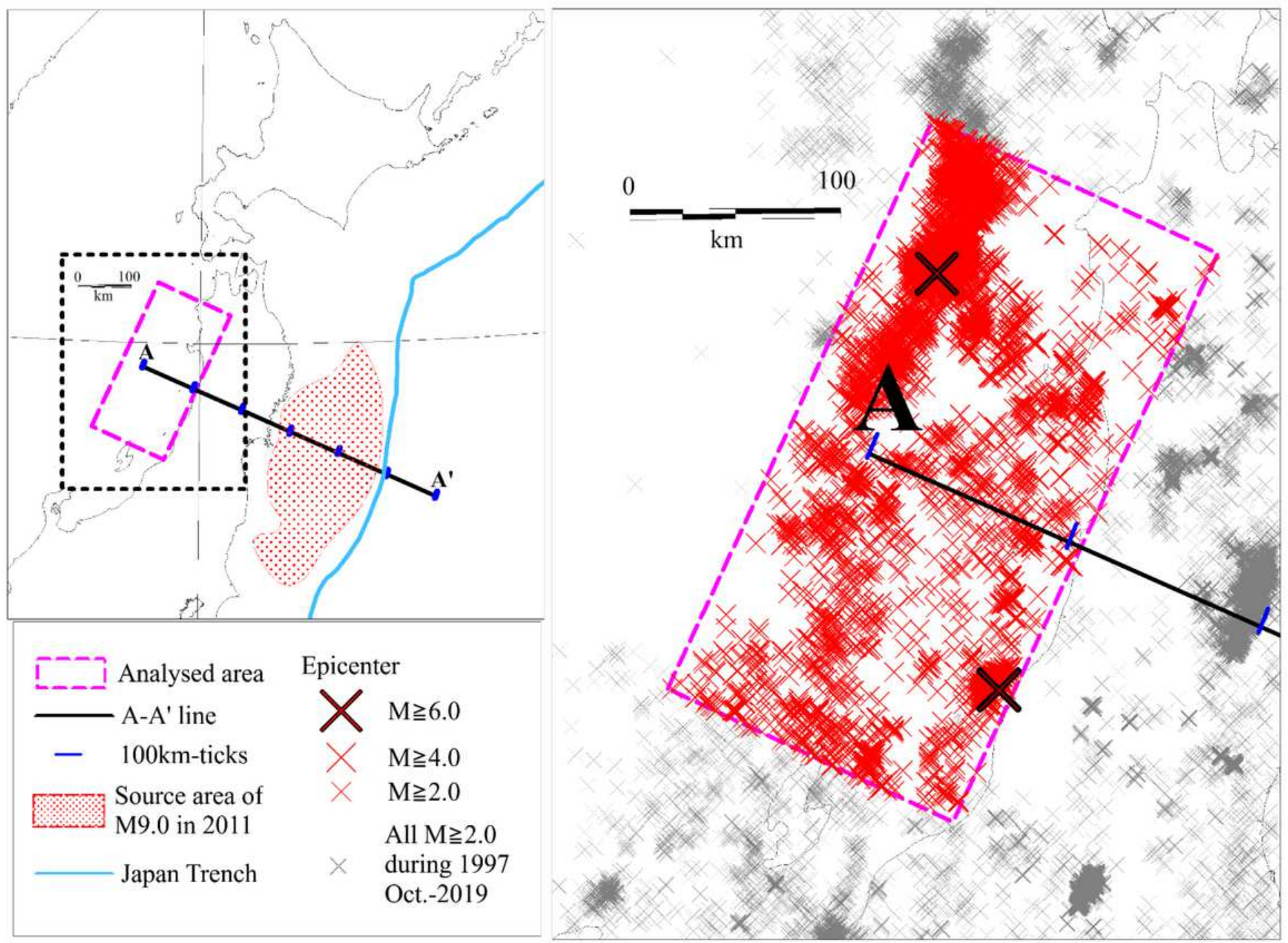

Fig. 1

\section{Figure 1}

The map of the examined area, and the distribution of examined shallow earthquakes. All $M>=2.0$ earthquakes of depth $=<60 \mathrm{~km}$ in JMA catalog from Oct. 1st, 1997, to Dec. 31st, 2019 in the black dotted square of the left map are shown by gray crosses in the right large map. Red crosses are analyzed earthquakes. M6.4 on 2012 Mar. 12 (JST) in the north, and M6.7 on 2019 June 18 in the southeast are the only two $M \geq 6.0$ events. Source area of the megathrust $M 9$ event in 2011 is after Hashimoto et al. (2012). Ticks for each $100 \mathrm{~km}$ are shown for the A-A' line, which is parallel to the PAC-plate motion, is the same as the line in Fig. 7 of Hashima et al. (2014). 

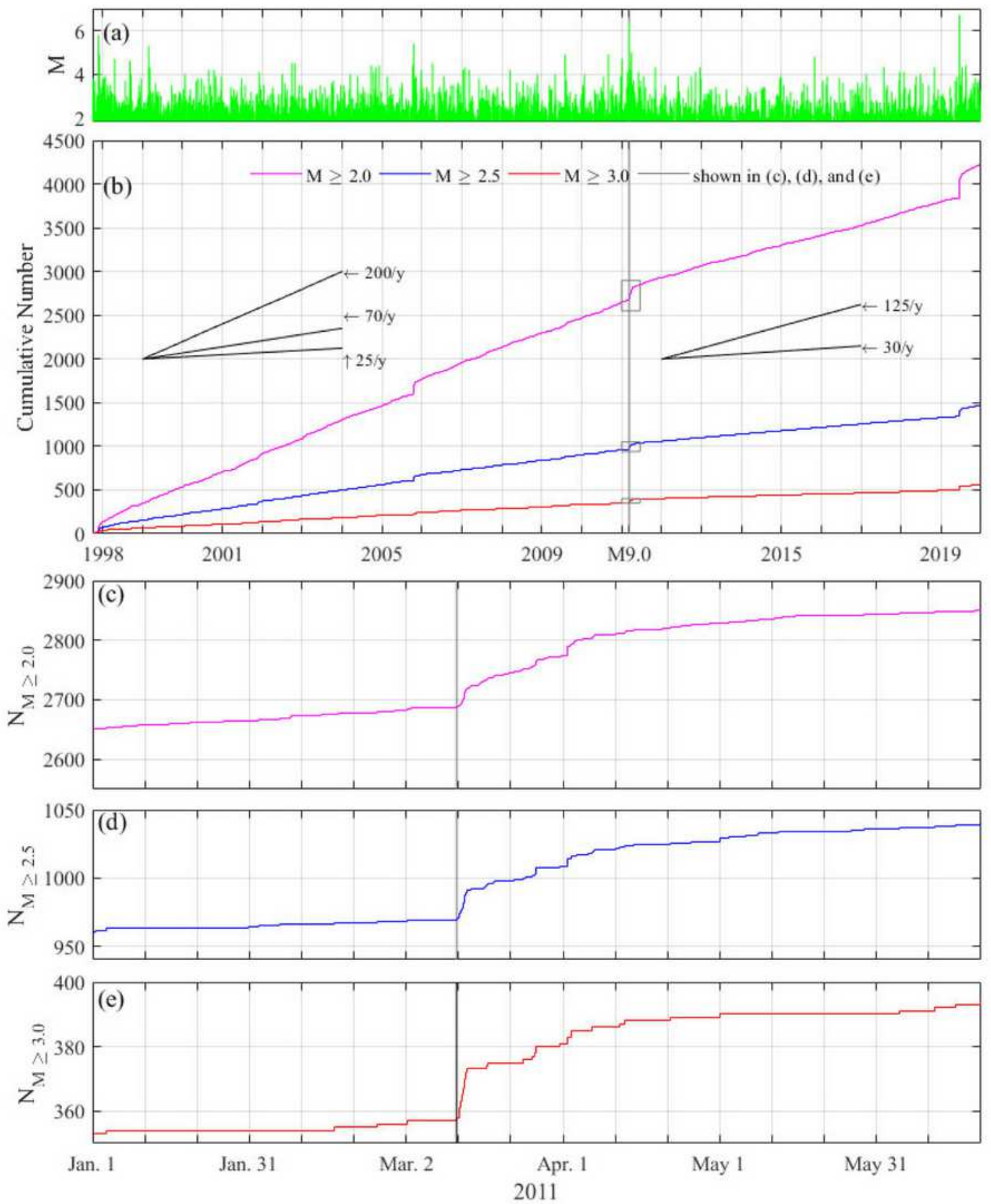

Fig. 2.

\section{Figure 2}

Cumulative number of events shown by red crosses in Fig. 1. (a) M-T plot of events. (b) Cumulative numbers of the whole term with three thresholds of $\mathrm{M}$. For the period around the occurrence time of the M9 event (shown by gray squares on each line) are expanded in (c), (d) and (e), respectively. The slope of five occurrence rates are shown by black lines as references to see rates from cumulative number lines. 

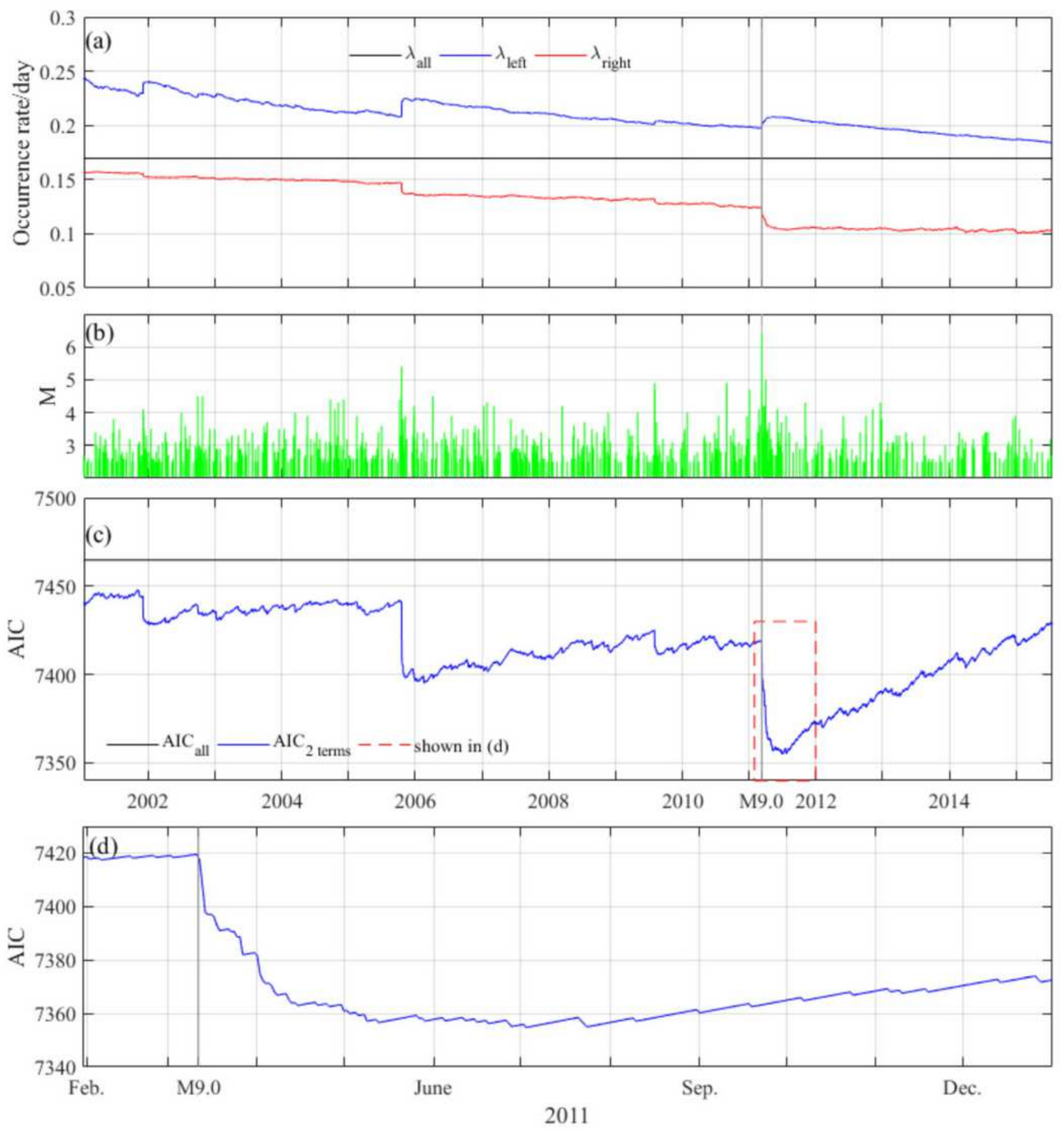

Fig. 3

\section{Figure 3}

Occurrence rates and AIC at each Tc for $M \geq 2.5$. (a) Daily occurrence rate of before Tc (Blue line) and after Tc (Red line) terms are shown at each Tc. Black line shows the average rate of the whole term. (b) M-T plot of $\mathrm{M} \geq 2.5$ for the same period. (c) AIC values for each Tc are plotted at Tc. The black line shows the AIC for the model without Tc, i.e. the constant rate through the whole term. The part in the red broken square are expanded in (d). 

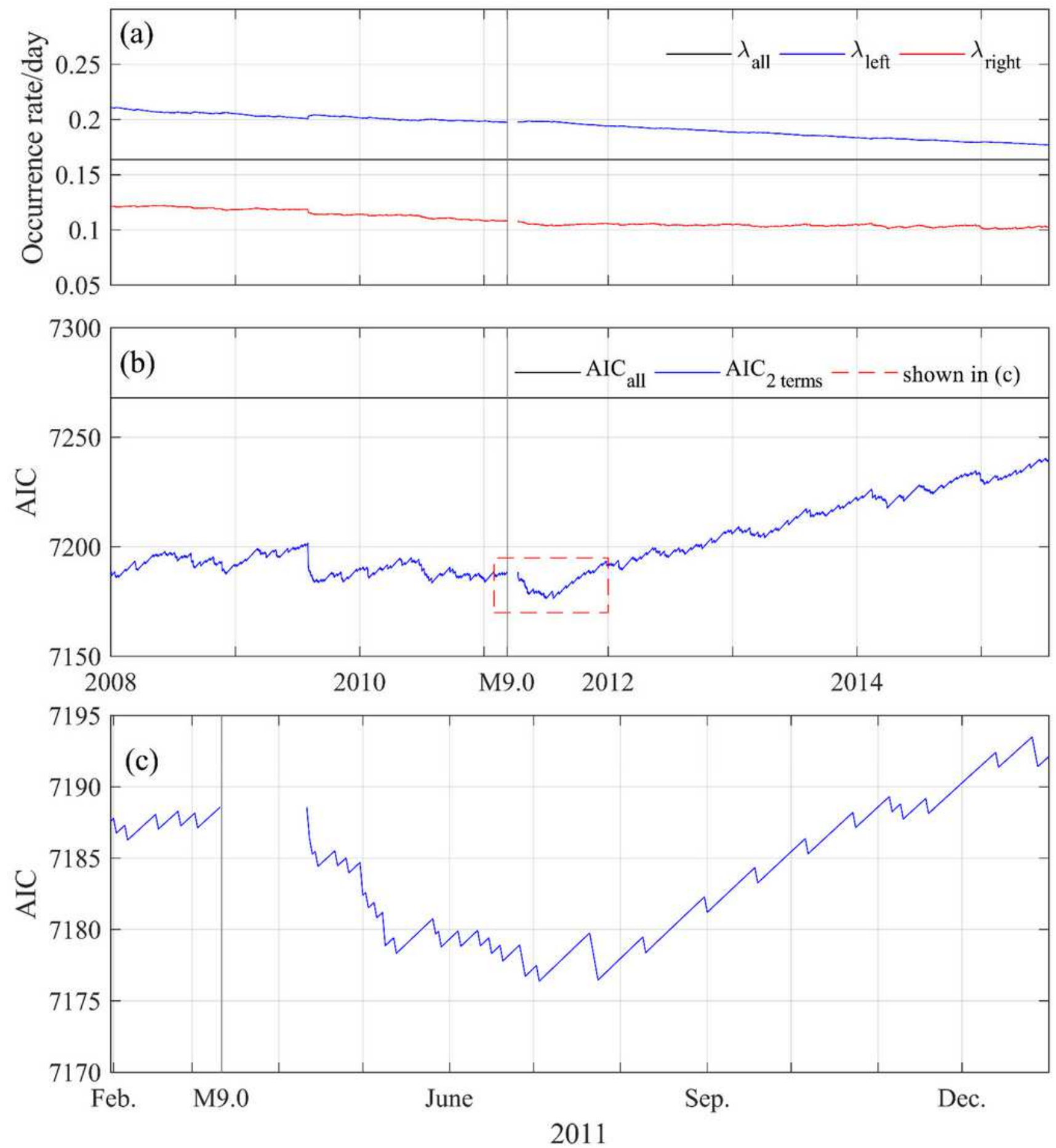

Fig. 4.

\section{Figure 4}

Occurrence rates and AIC at each Tc for $\mathrm{M} \geq 2.5$ without one month data after the $\mathrm{M} 9$ event. Tc in July 2011 gives the smallest AIC. See the caption of Fig. 3. 

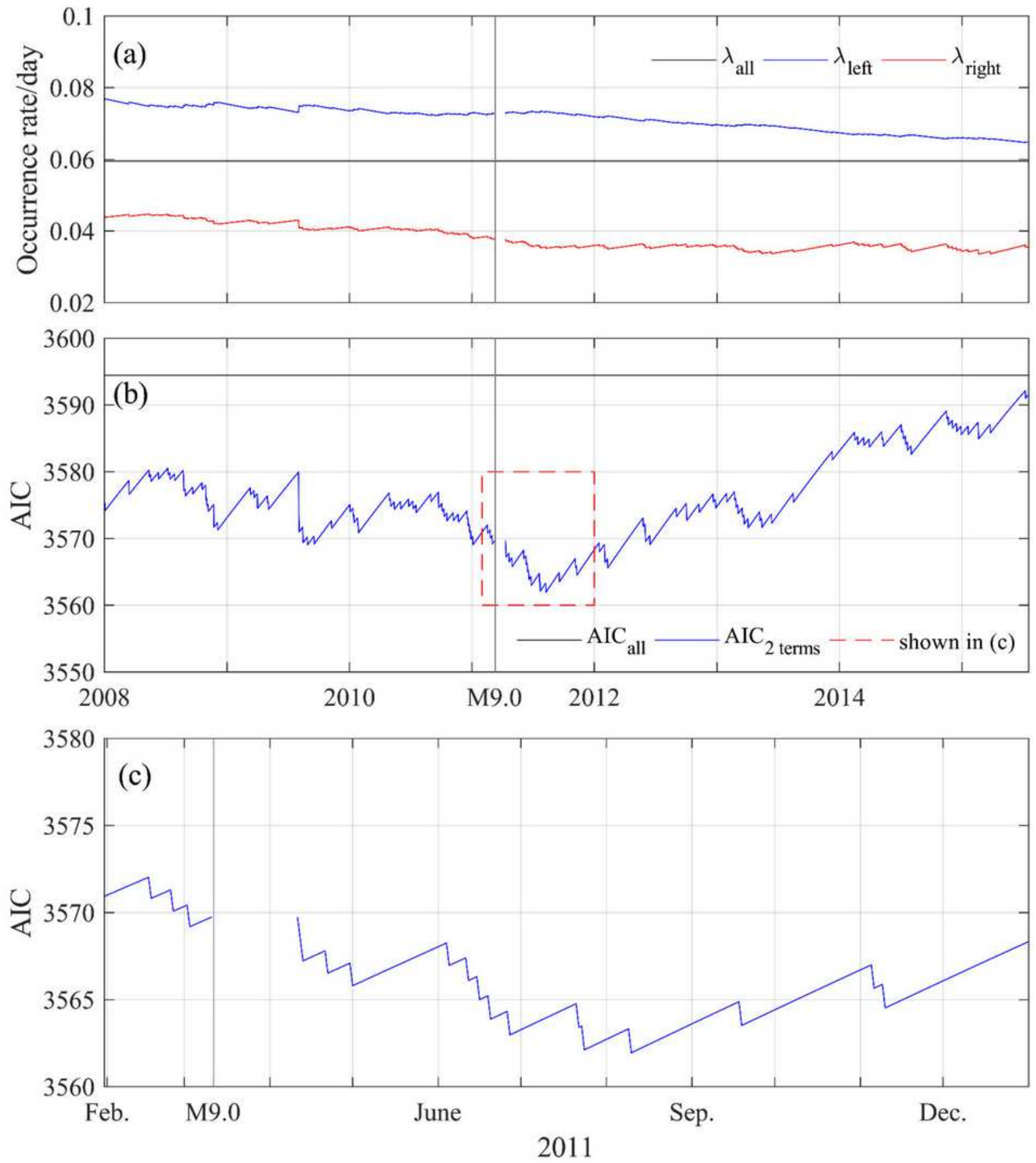

Fig. 5.

\section{Figure 5}

Occurrence rates and AIC at each Tc for $\mathrm{M} \geq 3.0$ without one month data after the $M 9$ event. Tc in Aug. 2011 gives the smallest AIC. See the caption of Fig. 3 

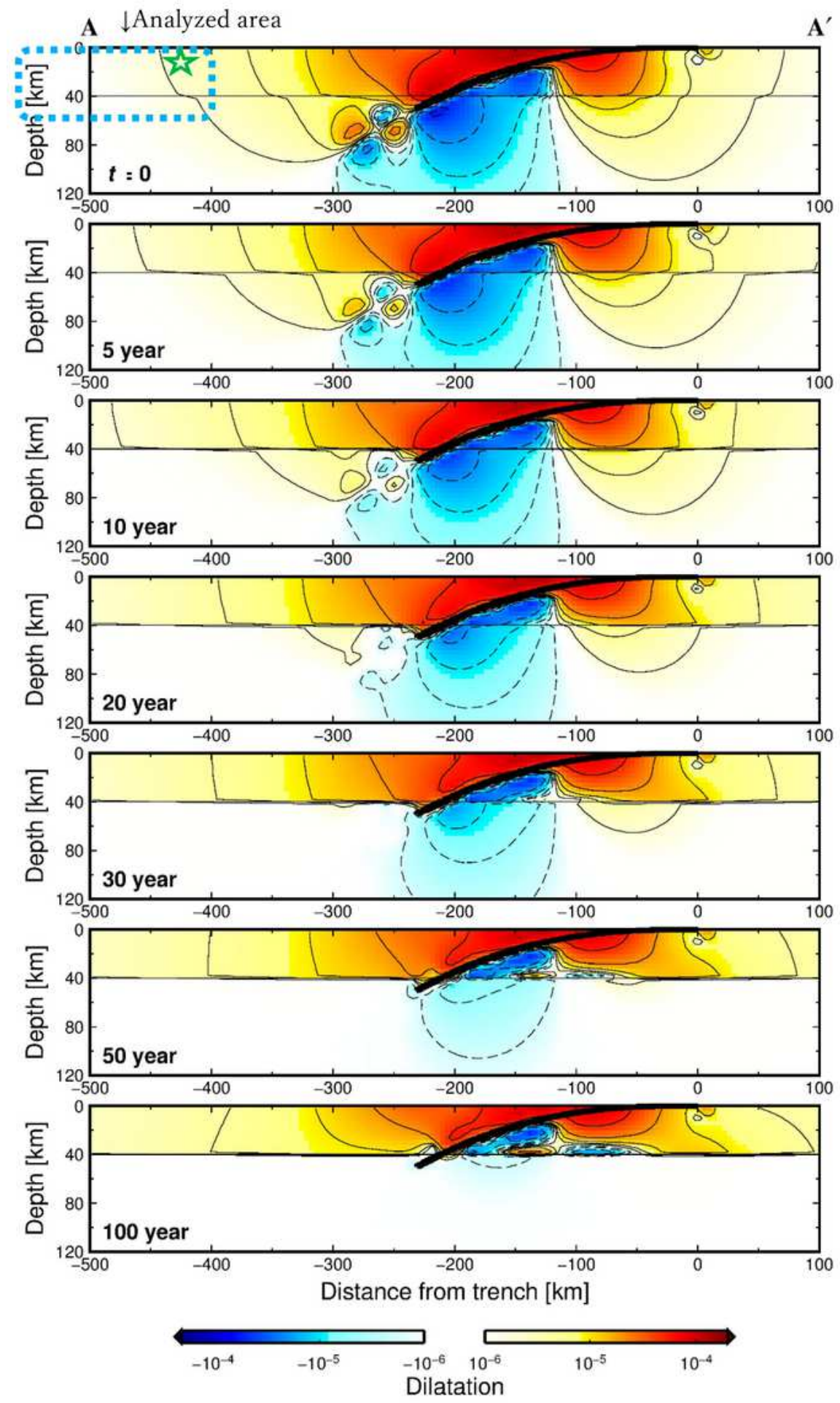

Fig. 6.

\section{Figure 6}

Temporal changes of the isotropic strain due to the $\mathrm{M} 9$ event. The vertical section of the isotropic strain changes along the line A-A' in Fig. 1 at $t=0$ (coseismic), 5, 10, 20, 30, 50, and 100 years after the M9 event are shown by color and contours. The red and blue color scales represent expansion, and contraction, respectively. Contours of $5 \times 10-5, \pm 2 \times 10-5, \pm 1 \times 10-5, \pm 5 \times 10-6, \pm 2 \times 10-6$ are also shown by thin lines. The thick solid line indicates the PAC plate interface shallower than $50 \mathrm{~km}$. The thin horizontal line at $40 \mathrm{~km}$ - 
depth indicates the interface between elastic and viscoelastic layers. The analyzed area is shown by the blue dotted rectangle in the top figure. The green star in the top figure shows the position of the point whose stress change is plotted in Fig. 8. [made after Hashima et al. (2014)]

\section{Figure 7}

Deviatoric shear strain changes due to the M9 event. The vertical section of the deviatoric strain fields along the line A-A' in Fig. 1 at $t=0$ (coseismic), 5, 10, 20, 30, 50, and 100 years after the M9 event. The deviatoric maximum shear strain is shown by color, and contours of $5 \times 10-5,2 \times 10-5,1 \times 10-5,5 \times 10-6$, and, $2 \times 10-6$. The black and white bars show the extension and contraction directions with those magnitudes at each point, respectively. See the caption of Fig. 6 .

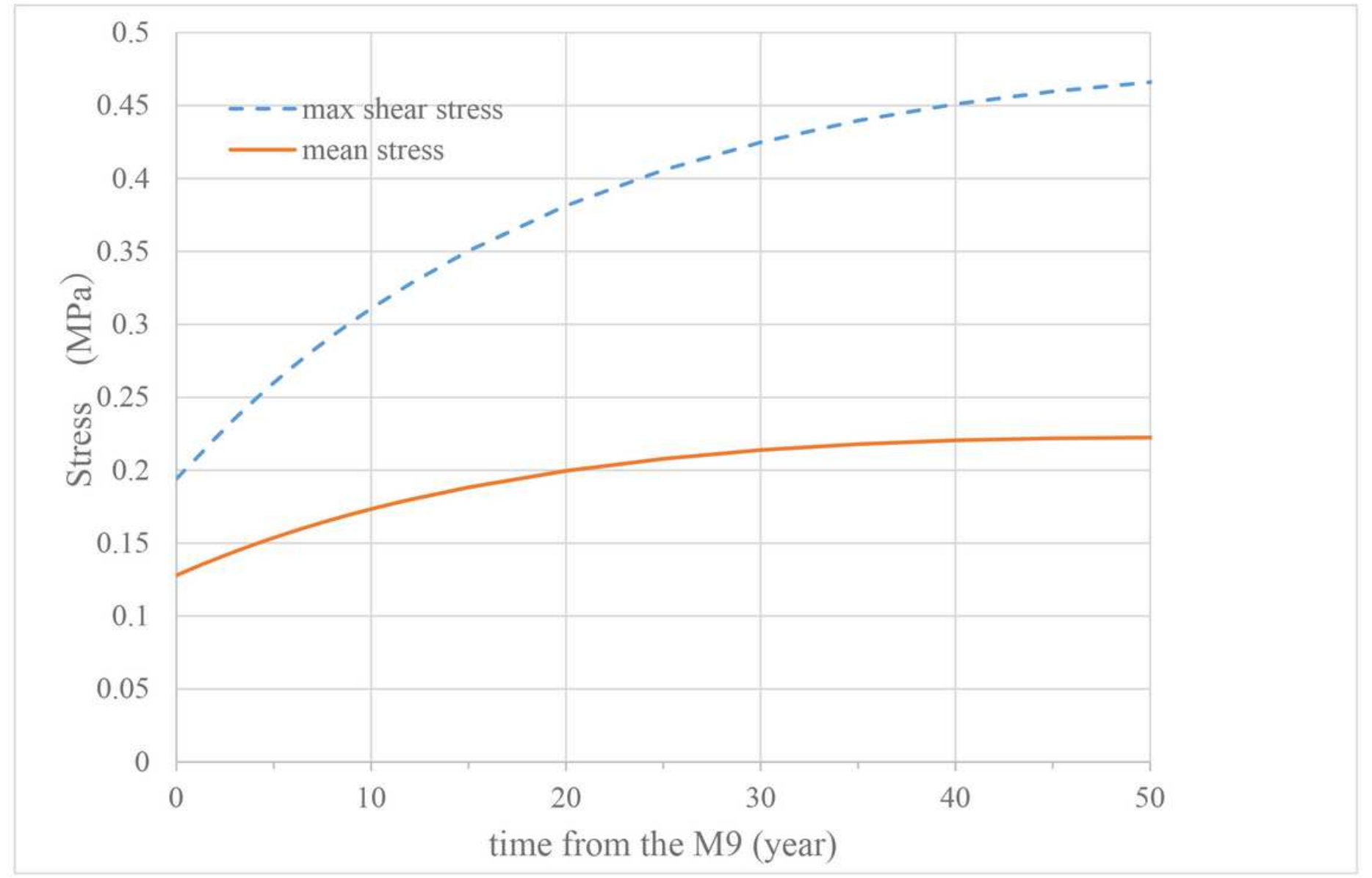

Fig. 8.

\section{Figure 8}

Changes of the mean stress (extension positive), and the maximum shear stress at the point of (422kmwest from the trench axis, 10km-depth) shown in Fig. 6 due to the M9 event, for 50 years. Since the point is in the elastic layer, dilatation and the maximum shear strain are proportional to the mean stress, and 
the maximum shear stress, respectively. With the bulk and shear moduli in Table 3, these are converted to stresses. The values at $\mathrm{t}=0$ are coseismic values.

\section{Supplementary Files}

This is a list of supplementary files associated with this preprint. Click to download.

- AdditionalFiles.pdf

- GraphicAbstract.png 